Review began 11/22/2021 Review ended 11/27/2021 Published 12/01/2021

๑) Copyright 2021

Al Ghadeer et al. This is an open access article distributed under the terms of the Creative Commons Attribution License CCBY 4.0., which permits unrestricted use, distribution, and reproduction in any medium, provided the original author and source are credited.

\section{Pregnancy-Related Anxiety and Impact of Social Media Among Pregnant Women Attending Primary Health Care}

Hussain A. Al Ghadeer ${ }^{1}$, Nihad A. Al Kishi ${ }^{2}$, Duaa M. Almubarak ${ }^{3}$, Zainab Almurayhil ${ }^{3}$, Fatimah Alhafith 3 , Bayan Abduljaleel Al Makainah ${ }^{3}$, Kholoud H. Algurini ${ }^{2}$, May M. Aljumah ${ }^{2}$, Maria M. Busaleh ${ }^{4}$, Nouh A. Altaweel $^{3}$, Mohammed H. Alamer ${ }^{3}$

1. Pediatrics, Maternity and Children Hospital, Al-Ahsa, SAU 2. Obstetrics and Gynaecology, Maternity and Children Hospital, Al-Ahsa, SAU 3. Obstetrics and Gynaecology, King Faisal University, Al-Ahsa, SAU 4. Family Medicine, AlAhsa Health Cluster, Al-Ahsa, SAU

Corresponding author: Hussain A. Al Ghadeer, hu.alghadeer@gmail.com

\section{Abstract \\ Background}

Pregnant women go through physiological as well as psychological changes during pregnancy. Antenatal anxiety disorders are common, with proven adverse maternal and fetal outcomes. Anxiety increases the risks for prematurity and neurodevelopmental disorders. This study aimed to estimate the prevalence of pregnancy-related anxiety and the impact of social media among pregnant women in Al-Ahsa, Saudi Arabia.

\section{Materials and methods}

This observational cross-sectional study included pregnant women who were attending antenatal care (ANC) in primary healthcare centers between May and October of 2021 in Al-Ahsa, Saudi Arabia. For data collection, a structured self-administered questionnaire was distributed randomly to eligible pregnant women. The presence of pregnancy-related anxiety was assessed by using the 10-item Pregnancy-Related Anxiety Questionnaire-Revised (PRAQ-R), Arabic version. The impact of social media was measured through Social Media Engagement Questionnaire (SMEQ).

\section{Results}

Out of 823 pregnant women, 382 were eligible. Their mean age was $26.1 \pm 10.9$ years. Most of them (70.4\%) had adhered to ANC. However, $32.1 \%$ had a history of miscarriage, and $6.7 \%$ had previous birth with congenital anomalies. The mean scores of pregnancy-related anxiety domains were 10.6 out of 15 for fear of giving birth, 8.7 for concern of own appearance, and 6.4 out of 12 for worries about bearing a handicapped child. More than half of the participants scored 28 out of 50 for pregnancy-related anxiety. The factors that were significantly associated with pregnancy-related anxiety were healthcare workers, first trimester, and unplanned pregnancy $(\mathrm{P}<0.05)$. Social media engagement showed no correlation with anxiety.

\section{Conclusions}

The pregnancy-related anxiety level was average among pregnant women in Al-Ahsa, and fear of giving birth was the most common reason. Its predictors included early pregnancy, being a healthcare provider, and unplanned pregnancy. Pregnancy-related anxiety should be diagnosed early during routine ANC for better maternal and fetal outcomes.

Categories: Family/General Practice, Obstetrics/Gynecology, Psychiatry

Keywords: al-ahsa, saudi arabia, social media, pregnancy, anxiety

\section{Introduction}

Pregnancy is the most important and challenging period among women willing to raise a child [1]. Pregnant women experience several physical changes such as weight gain and changes in body appearance; psychological changes such as stress, anxiety, and depression; and also hormonal changes [2]. Therefore, women are recommended to prepare themselves physically and mentally so they can go through such a critical and life-changing period safely without facing any complications. Such complications include miscarriage, low birth weight, impaired cognitive and physical fetal development, and possibly death [3-5]. Nonetheless, following a healthy lifestyle and maintaining mental well-being and peace of mind can make pregnancy a positive and rewarding experience $[1,6]$. In fact, social media can greatly influence such an important period of life for many women either positively or negatively.

Social media is a huge internet-based platform that offers fast digital communication and widespread information, images, and video clips, which can all be easily and quickly accessed through smartphones, 
among internet users [6]. In Saudi Arabia, the number of social media users is increasing by 2.1 million annually. In addition, approximately $80 \%$ of the total population in Saudi Arabia uses social media [7]. Pregnant women do use social media for several purposes, such as emotional support, social support, and improvement in health literacy, especially information related to pregnancy. They can certainly benefit from social media usage. One of the benefits of social media is the provision of social support, which can be greatly helpful for preventing pregnancy-related anxiety and maintaining a positive mood throughout pregnancy [8]. Conversely, social media can negatively impact the physical and psychological well-being of a pregnant woman, especially when the information is from unreliable sources and not provided by a healthcare practitioner. Furthermore, the vast amount of information from social media sometimes may have opposing views; hence, with constant viewing, it leads to a sense of mistrust, which can trigger anxiety and mental stress [9].

Therefore, the pregnancy period is the most sensitive stage in women's lives, and pregnant women are highly at risk of developing psychological changes, which may lead to unfavorable consequences, such as preterm delivery, low birth weight, and postpartum depression [10,11]. In Saudi Arabia, the most prevalent psychological disorders during pregnancy are anxiety and depression, accounting for $23.6 \%$ and $26.8 \%$, respectively. Unemployed women, as well as those with an unplanned pregnancy and recurrent miscarriage, have a high risk for depression and anxiety during pregnancy [12].

Hence, pregnancy-related anxiety is among the most prevalent mental conditions. This condition refers to an undesirable emotional state associated with multiple worries about childbirth, the baby's health, and healthcare experience during pregnancy and birth [13]. Anxiety symptoms such as poor sleep and tiredness are common during pregnancy, and up to $54 \%$ of pregnant women are at risk for these symptoms $[13,14]$. In Kuwait, the prevalence of pregnancy-related anxiety was 15\% [15], whereas in India, it was 55\%, which is considered high, especially before the gestational age of 24 weeks [16]. Pregnancy-related anxiety mimics many conditions; thus, this diagnosis may be overlooked, leading to negative pregnancy outcomes such as prolonged labor, preterm delivery, and cesarean section. Therefore, screening and early detection of anxiety are critical during pregnancy to prevent complications [17]. The Pregnancy-Related Anxiety QuestionnaireRevised 2 (PRAQ-R2) is a valid assessment scale used for detecting pregnancy-related anxiety for both nulliparous and parous women [18]. Accordingly, measuring the prevalence of pregnancy-related anxiety and assessing its relationship with social media addiction in Al-Ahsa, the eastern province of Saudi Arabia, are crucial to take preventive measures in the future.

\section{Materials And Methods}

\section{Aim}

This study aimed to explore the psychological impacts of pregnancy and social media influence among pregnant women attending primary health care in Al-Ahsa, Saudi Arabia.

\section{Study design and participants}

This descriptive cross-sectional study was conducted in primary healthcare centers in Al-Ahsa, Saudi Arabia, between May and October of 2021. Any pregnant women (primigravida or multigravida) aged above 18 years and not diagnosed recently or previously with comorbidities or psychological diseases were included. Any pregnant women aged less than 18 years old and diagnosed with psychological illness were excluded from the research.

\section{Data collection instrument and procedures}

Data were collected at the primary healthcare centers. All participants provided informed consent and had autonomy for rejection. The privacy and confidentiality of results were maintained. The Institutional Review Board of King Fahad Hospital-Hofuf in Al-Ahsa approved this study (NO: 34-EP-2021). The participants were requested to fill an online or paper-based questionnaire. The survey was composed of four sections. The first section is about patient demographics (age, gender, and education level), the second section is about obstetric history (gestational age, regular follow-up on antenatal care [ANC], and history of abortion or congenital anomalies), the third section is about pregnancy-related anxiety using the 10-item PRAQ-R, Arabic version [19,20], and the fourth section is about social media engagement using the Arabic version of the Social Media Engagement Questionnaire (SMEQ) [21,22]. Each item in the PRAQ-R is answered using a five-point Likert scale (from 1 as "definitely not true" to 5 as "definitely true") for measuring three subscales: fear of giving birth (three questions); worries about bearing a physically or mentally handicapped child (four questions); and concern of own appearance (three questions). Meanwhile, the SMEQ is a brief, valid, and effective psychometric instrument used for assessing the levels of personal use of social media by measuring the extent to which people's key daily activities tend to involve social media. It consists of five items that measure social media usage patterns throughout different parts of the day. These items were rated on a seven-point scale, with 0 as "never" and 7 as "seven times."

\section{Data analysis}

The data were extracted, revised, coded, and fed to the statistical software IBM SPSS, version 22 (SPSS Inc. 


\section{Cureus}

Chicago, IL). All statistical analyses were conducted using two-tailed tests. A P-value of less than 0.05 was considered statistically significant. The total and subscale scores of PRAQ-R2 were calculated. The PRAQ-R2 has 10 items, and the subscale scores are 3-15 for fear of giving birth (F1, three items), 4-20 for worries about bearing a physically or mentally handicapped child (F2, four items), and 3-15 for concern about own appearance (F3, three items). The overall score ranges from 10 to 50. Mean scores with standard deviation and score percentage of the total were calculated for each factor and overall. As for SMEQ, an individual's composite mean days of use for each item was calculated as the range and standard deviation of the overall engagement days per week. The different factors associated with pregnancy-related anxiety levels were assessed by multivariable analysis, and the significance was determined by one-way ANOVA and independent samples t-test. The relationship between pregnant women's anxiety score and their average number of social media engagement days per week was evaluated by correlation analysis with scatter distribution.

\section{Results}

A total of 382 pregnant women met the inclusion criteria and completed the study questionnaire. Their ages ranged from 18 to 46 years, with a mean age of $26.1 \pm 10.9$ years. Slightly more than half of them (228, $59.7 \%$ ) were university graduates or postgraduates. Regarding occupation, most of them were housewives (281, 73.6\%). In addition, 58 (15.2\%) were non-healthcare workers, whereas 43 (11.3\%) were healthcare workers. Majority had a monthly income of 5,000-10,000 SR (197, 51.6\%), followed by below 5,000 SR (113, 29.6\%) and above 20,000 SR (9, 2.4\%) (Table 1).

\begin{tabular}{|c|c|c|}
\hline Socio-demographic data & No & $\%$ \\
\hline \multicolumn{3}{|l|}{ Age in years } \\
\hline $18-25$ & 101 & $26.4 \%$ \\
\hline $26-30$ & 140 & $36.6 \%$ \\
\hline $31-39$ & 123 & $32.2 \%$ \\
\hline $40+$ & 18 & $4.7 \%$ \\
\hline \multicolumn{3}{|l|}{ Educational level } \\
\hline Below university & 154 & $40.3 \%$ \\
\hline University/above & 228 & $59.7 \%$ \\
\hline \multicolumn{3}{|l|}{ Job title } \\
\hline Housewife & 281 & $73.6 \%$ \\
\hline Non-healthcare worker & 58 & $15.2 \%$ \\
\hline Healthcare worker & 43 & $11.3 \%$ \\
\hline \multicolumn{3}{|l|}{ Monthly income } \\
\hline$<5,000 \mathrm{SR}$ & 113 & $29.6 \%$ \\
\hline $5,000-10,000$ SR & 197 & $51.6 \%$ \\
\hline 10,000-20,000 SR & 63 & $16.5 \%$ \\
\hline$>20,000 \mathrm{SR}$ & 9 & $2.4 \%$ \\
\hline
\end{tabular}

TABLE 1: Socio-demographic data of pregnant females, Al-Ahsa, Saudi Arabia.

Regarding obstetric history (Table 2), 83 (21.7\%) of the participants were primigravida. Additionally, 101 (26.4\%) were in their first trimester, and 139 (36.4\%) were in their third trimester. The majority (269, $70.4 \%)$ of the participants reported being always adherent to ANC appointments, whereas only one reported never going to ANC visits. In the current pregnancy, $71(18.6 \%)$ had complications, and only two used in vitro fertilization (IVF). The current pregnancy was previously planned among 203 (53.1\%) females. Furthermore, 89 (29.8\%), 96 (32.1\%), and 20 (6.7\%) participants reportedly had a previous pregnancy or childbirth complications, a history of miscarriage or stillbirth, and a history of giving birth with congenital anomalies, respectively. 


\section{Cureus}

Obstetric history

Is this being your first pregnancy?

Yes

No

Gestational age of the pregnancy

First trimester (1-13 weeks)

Second trimester (14-26 weeks)

Third trimester (27-40 weeks)

Do you adhere to your appointments in antenatal care?

\section{Always}

Often

Sometimes

Never

Do you have complications in your current pregnancy?

Yes

Have you used in vitro fertilization (IVF) for the current pregnancy?

Yes

No

Is this current pregnancy previously planned?

Have you ever had any complications during pregnancy or childbirth?

Yes

Have you ever had a miscarriage or stillbirth?

Yes

Have you ever had congenital anomalies?

TABLE 2: Obstetric history among pregnant females, Al-Ahsa, Saudi Arabia.

The results of PRAQ-R2 are presented in Table 3. Concerning the fear of giving birth, most of the participants (92.7\%) were worried about the pain of contractions and the pain during delivery, which was reasonable to very relevant among $69.4 \%$ of them. The majority (92.4\%) of participants also worried about delivery, which was relevant among $66.8 \%$. Additionally, $75.4 \%$ were worried about not being able to control themselves during labor and afraid that they would scream. Regarding worries about bearing a handicapped child, 59.2\% sometimes thought that their baby would be in poor health or prone to illnesses; similar results were obtained regarding fear of physical defect or physical limitation in the newborn (46.3\%), fear of stillborn or infant death during or immediately after delivery (44.5\%), and fear of mental disability or brain damage (43.7\%). With regard to concern about their own appearance, they were mostly worried that they 


\section{Cureus}

shall not regain their pre-pregnancy figure after delivery (80.4\%), followed by worry about gaining an enormous weight (72\%) and worry about their unattractive appearance (63.1\%).

\begin{tabular}{|c|c|c|c|c|c|c|c|c|c|c|c|}
\hline \multirow[t]{2}{*}{ Domain } & \multirow[t]{2}{*}{ Items } & \multicolumn{2}{|c|}{$\begin{array}{l}\text { Absolutely } \\
\text { not } \\
\text { relevant }\end{array}$} & \multicolumn{2}{|c|}{$\begin{array}{l}\text { Hardly } \\
\text { ever } \\
\text { relevant }\end{array}$} & \multicolumn{2}{|c|}{$\begin{array}{l}\text { Sometimes } \\
\text { relevant }\end{array}$} & \multicolumn{2}{|c|}{$\begin{array}{l}\text { Reasonably } \\
\text { relevant }\end{array}$} & \multicolumn{2}{|c|}{$\begin{array}{l}\text { Very } \\
\text { relevant }\end{array}$} \\
\hline & & No & $\%$ & No & $\%$ & No & $\%$ & No & $\%$ & No & $\%$ \\
\hline \multirow{3}{*}{$\begin{array}{l}\text { Fear of giving } \\
\text { birth }\end{array}$} & I am anxious about the delivery. & 29 & $7.6 \%$ & 13 & $3.4 \%$ & 85 & $22.3 \%$ & 176 & $46.1 \%$ & 79 & $20.7 \%$ \\
\hline & $\begin{array}{l}\text { I am worried about the pain of contractions } \\
\text { and the pain during delivery. }\end{array}$ & 28 & $7.3 \%$ & 25 & $6.5 \%$ & 68 & $17.8 \%$ & 129 & $33.8 \%$ & 132 & $34.6 \%$ \\
\hline & $\begin{array}{l}\text { I am worried about not being able to control } \\
\text { myself during labor and fear that I will } \\
\text { scream. }\end{array}$ & 94 & $24.6 \%$ & 36 & $9.4 \%$ & 64 & $16.8 \%$ & 108 & $28.3 \%$ & 80 & $20.9 \%$ \\
\hline \multirow{4}{*}{$\begin{array}{l}\text { Worries about } \\
\text { bearing a } \\
\text { handicapped } \\
\text { child }\end{array}$} & $\begin{array}{l}\text { I sometimes think that our child will be in poor } \\
\text { health or will be prone to illnesses. }\end{array}$ & 156 & $40.8 \%$ & 49 & $12.8 \%$ & 86 & $22.5 \%$ & 65 & $17.0 \%$ & 26 & $6.8 \%$ \\
\hline & $\begin{array}{l}\text { I am afraid the baby will be mentally } \\
\text { handicapped or will suffer from brain damage. }\end{array}$ & 215 & $56.3 \%$ & 30 & $7.9 \%$ & 65 & $17.0 \%$ & 41 & $10.7 \%$ & 31 & $8.1 \%$ \\
\hline & $\begin{array}{l}\text { I am atraid our baby will be stillborn or will die } \\
\text { during or immediately after delivery. }\end{array}$ & 212 & $55.5 \%$ & 36 & $9.4 \%$ & 67 & $17.5 \%$ & 40 & $10.5 \%$ & 27 & $7.1 \%$ \\
\hline & $\begin{array}{l}\text { I am afraid that our baby will suffer from a } \\
\text { physical defect or worry that something will } \\
\text { be physically wrong with the baby. }\end{array}$ & 205 & $53.7 \%$ & 28 & $7.3 \%$ & 62 & $16.2 \%$ & 48 & $12.6 \%$ & 39 & $10.2 \%$ \\
\hline \multirow{3}{*}{$\begin{array}{l}\text { Concern about } \\
\text { own appearance }\end{array}$} & $\begin{array}{l}\text { I am worried about the fact that I shall not } \\
\text { regain my figure after delivery. }\end{array}$ & 75 & $19.6 \%$ & 28 & $7.3 \%$ & 97 & $25.4 \%$ & 110 & $28.8 \%$ & 12 & $18.8 \%$ \\
\hline & $\begin{array}{l}\text { I am concerned about my unattractive } \\
\text { appearance. }\end{array}$ & 141 & $36.9 \%$ & 33 & $8.6 \%$ & 93 & $24.3 \%$ & 80 & $20.9 \%$ & 35 & $9.2 \%$ \\
\hline & I am worried about my enormous weight gain. & 107 & $28.0 \%$ & 38 & $9.9 \%$ & 80 & $20.9 \%$ & 92 & $24.1 \%$ & 65 & $17.0 \%$ \\
\hline
\end{tabular}

TABLE 3: Results of self-reported 10 items Pregnancy-Related Anxiety Questionnaire-Revised 2 (PRAQ-R2).

Table 4 summarizes the three subscale scores. The mean scores for fear of giving birth, worries about bearing a handicapped child, and concern about own appearance were 10.6 (70.7\%), 6.4 (53.3\%), and 8.7 (58\%), respectively. The mean anxiety score was 28 out of 50 (56\%).

\begin{tabular}{|c|c|c|c|c|}
\hline Subscale & Range & Mean & SD & Score \% \\
\hline Fear of giving birth & 3-15 & 10.6 & 3.0 & $70.7 \%$ \\
\hline Worries about bearing a handicapped child & 4-12 & 6.4 & 2.4 & $53.3 \%$ \\
\hline Concern about own appearance & 3-15 & 8.7 & 3.5 & $58.0 \%$ \\
\hline Overall score & $10-50$ & 28.0 & 9.2 & $56.0 \%$ \\
\hline
\end{tabular}

TABLE 4: Pregnancy-related anxiety among pregnant females, Al-Ahsa, Saudi Arabia. 


\section{Cureus}

$60.0 \%$

$50.0 \%$

$48.7 \%$

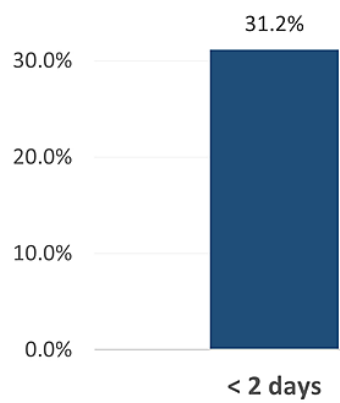

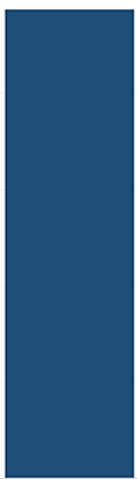

2-4 days

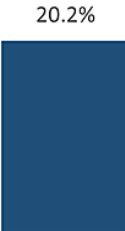

5-7 days

FIGURE 1: Social media engagement among pregnant females per week, Al-Ahsa, Saudi Arabia.

The factors associated with pregnancy-related anxiety among these pregnant women are presented in Table 5. The anxiety score was significantly higher among those working as healthcare workers (31.7) than as housewives (27.5) and non-healthcare workers (27.4) $(\mathrm{P}=0.016)$. Those in their first trimester had a higher mean anxiety score than those in their third trimester (29.8 vs. 26.3; $\mathrm{P}=0.012$ ). Pregnant women with high adherence to ANC visits had significantly higher anxiety scores than those who never adhered (30.5 vs. 22.0; $\mathrm{P}=0.001$ ). The anxiety score was also higher in those with unplanned pregnancies than in those with planned pregnancies $(29.2$ vs. $26.9 ; \mathrm{P}=0.016)$. Other factors were insignificantly associated with pregnancyrelated anxiety levels.

\begin{tabular}{|c|c|c|c|}
\hline \multirow{2}{*}{ Factors } & \multicolumn{2}{|c|}{ Anxiety score } & \multirow{2}{*}{ P-value } \\
\hline & Mean & SD & \\
\hline \multicolumn{4}{|l|}{ Age in years } \\
\hline $18-25$ & 27.1 & 9.1 & \multirow{4}{*}{.650} \\
\hline $26-30$ & 28.0 & 8.7 & \\
\hline $31-39$ & 28.4 & 10.1 & \\
\hline $40+$ & 29.7 & 7.2 & \\
\hline \multicolumn{3}{|l|}{ Educational level } & \multirow{3}{*}{$.727^{\$}$} \\
\hline Below university & 27.8 & 9.0 & \\
\hline University/above & 28.1 & 9.4 & \\
\hline \multicolumn{4}{|l|}{ Job title } \\
\hline Housewife & 27.5 & 8.8 & \multirow{3}{*}{$.016^{*}$} \\
\hline Non-healthcare worker & 27.4 & 10.4 & \\
\hline Healthcare worker & 31.7 & 9.3 & \\
\hline \multicolumn{4}{|l|}{ Monthly income } \\
\hline$<5,000 \mathrm{SR}$ & 28.1 & 8.7 & \multirow{4}{*}{.491} \\
\hline $5,000-10,000$ SR & 27.6 & 9.7 & \\
\hline 10,000-20,000 SR & 29.3 & 8.4 & \\
\hline$>20,000$ SR & 25.6 & 9.8 & \\
\hline & & & \\
\hline
\end{tabular}




\section{Cureus}

Yes

No

Gestational age of the pregnancy

First trimester (1-13 weeks)

Second trimester (14-26 weeks)

Third trimester (27-40 weeks)

Do you adhere to your appointments in antenatal care?

Always

Often

Sometimes

Never

Do you have complications in your current pregnancy?

Yes

No

Is this current pregnancy previously planned?

Yes

No

Have you ever had any complications during pregnancy or childbirth?

Yes

No

Have you ever had a miscarriage or stillbirth?

Yes

No

Have you ever had congenital anomalies?

Yes

No

Social media engagement

$<2$

$2-4$

$5-7$

$\begin{array}{lll}28.2 & 10.1 & .827^{\$} \\ 27.9 & 9.0 & \end{array}$

$29.8 \quad 10.0$

$28.3 \quad 9.3$

$26.3 \quad 8.3$

$26.8 \quad 9.2$

$30.5 \quad 8.8 \quad .001^{*}$

$31.5 \quad 8.6$

$22.0 \quad 0.0$

$27.2 \quad 7.8 \quad .415^{\$}$

$28.1 \quad 9.5$

$26.9 \quad 9.5 \quad .016^{*, \$}$

$29.2 \quad 8.7$

$28.3 \quad 9.3 \quad .580^{\$}$

$27.7 \quad 8.8$

$27.5 \quad 9.9 \quad .553^{\$}$

$28.1 \quad 8.5$

$\begin{array}{lll}30.5 & 8.2 \quad .190^{\$}\end{array}$

$27.7 \quad 9.0$

$28.5 \quad 10.2$

$27.45 \quad 8.3$

$28.5 \quad 9.9$

TABLE 5: Factors associated with pregnancy-related anxiety among pregnant females, Al-Ahsa, Saudi Arabia.

$\mathrm{P}$ : one-way ANOVA; $\$$ : independent $\mathrm{t}$-test; ${ }^{*} \mathrm{P}<0.05$ (significant).

Figure 2 presents the correlation between pregnancy-related anxiety scores and average days of social media engagement among these pregnant women. As shown in the scatter diagram, their pregnancy-related anxiety had no significant correlation with their average use of social media per weekdays $(\mathrm{r}=0.12 ; \mathrm{P}=$ 0.341). 


\section{Cureus}

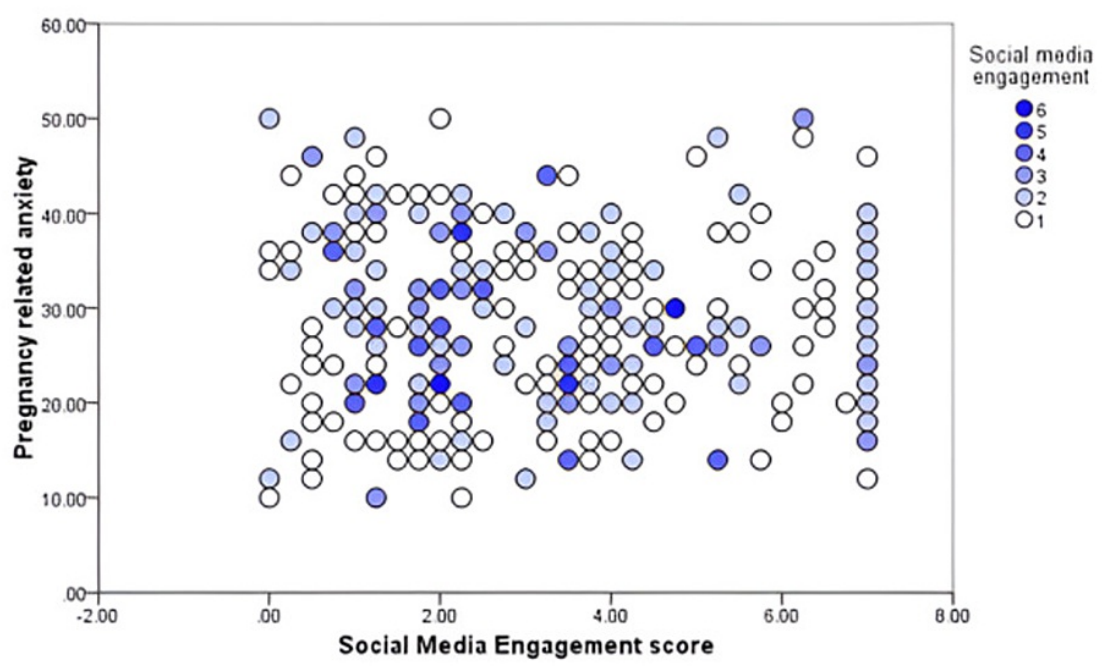

FIGURE 2: Social media engagement among pregnant females per week, Al-Ahsa, Saudi Arabia.

Discussion

This study assessed the pregnancy-related anxiety and the level of extended social media use in pregnant women living in Al-Ahsa, the eastern province of Saudi Arabia, and identified the factors associated with pregnancy-related anxiety. Pregnancy-related anxiety disorders are fairly common, with nearly $10 \%-15 \%$ of all pregnant women feeling some level of anxiety or stress during this major transitional phase in their lives [23]. The source of pregnant women's worry is future labor and expected pain in addition to fear of childbirth [24], worry about the health of the anticipated child, or the pregnancy-associated physical changes [25]. These stressors during pregnancy can negatively affect mothers' health and psychological well-being [26] as well as their future child. High pregnancy-related anxiety may end with unwanted pregnancy outcomes (preterm birth and low birth weight) [27].

In this study, the pregnant women generally had an average level of anxiety, obtaining a mean anxiety score of 28 out of 50 (56\%). Fear of giving birth obtained the highest level of anxiety. These women were worried about the pain of contractions and delivery and about the delivery process itself. The second item with the highest anxiety score was pregnant women's concern about their appearance. Pregnancy occurs with physiological and physical changes; thus, they were worried that they might not be able to regain their prepregnancy figure after delivery and might gain in weight enormously. The third was their worry about bearing a handicapped child. They were thinking that the child would be in poor health or prone to illnesses, afraid that the baby would suffer from a physical defect or something would be physically wrong with the baby, afraid that their baby would be stillborn or would die during or immediately after delivery, and afraid that the baby would be mentally handicapped or would suffer from brain damage. One of the factors that were significantly associated with high pregnancy-related anxiety in these pregnant women was being healthcare workers, which showed the highest level of anxiety because they are knowledgeable about delivery-related pain and difficulties and newborn risk of having congenital disorders or physical health problems. The second factor was early pregnancy. Pregnancy-related anxiety level was higher among women in their first trimester who were still unable to cope with pregnancy-related physical and psychological changes. The third factor was adherence to ANC visits; pregnant women with high anxiety levels showed higher adherence than those with low anxiety levels. The fourth factor was an unplanned pregnancy. Females with unplanned pregnancies showed higher levels of anxiety because such pregnancy was mostly unwanted. Perhaps, a family history of bad pregnancy outcomes or other family-related factors made them under stress for the upcoming baby.

These findings are concordant with many literature conclusions. Bayrampour et al. [28] studied pregnancyrelated anxiety through concept analysis and concluded that the most frequently reported dimensions included anxiety about fetal health, fetal loss, childbirth, parenting, and newborn care. In India, Nath et al. [17] reported a similar level of pregnancy-related anxiety among pregnant females where $55.7 \%$ manifested pregnancy-related anxiety. Lower socioeconomic status, low social support, and depression emerged as significant determinants of anxiety. In a prospective cohort study, Madhavanprabhakaran et al. [29] found that a U-pattern structure of pregnancy-specific anxiety was noticed all over trimesters of pregnancy, with nulliparous childbearing women showing the highest anxiety level. Adverse delivery outcomes such as prolonged labor, preterm labor, low birth weight, and unplanned cesarean section were associated with high pregnancy-related anxiety. A systematic review conducted by Jha et al. in 2018 [30] estimated the prevalence 
of anxiety during pregnancy at $1 \%-26 \%$ in low- and middle-income countries. However, published literature on anxiety during pregnancy seems to be limited. This highly variable range may be attributed to many factors, including the scale used to assess the anxiety level, phase of pregnancy at which the study was conducted, related health problems, and history of psychological disorders.

Considering social media engagement, the current study showed that roughly half of the pregnant females engaged in social media for two to four days per week, whereas only one-fifth (20.2\%) may use social media for five to seven days per week. Despite the high engagement, no significant association was found between the social media engagement rate and pregnant women's level of anxiety.

\section{Conclusions}

Pregnant women in the eastern province of Saudi Arabia showed an average level of pregnancy-related anxiety, which was mostly caused by fear of childbirth and concern about their appearance. Anxiety was significantly associated with early pregnancy, being healthcare workers (who were knowledgeable about pregnancy and newborn care), unplanned pregnancy, and adherence to ANC visits. In addition, their social media engagement rate was high but was not significantly associated with their anxiety level. Early assessment and detection, prevention, and management of pregnancy-related anxiety are necessary to enable women to cope with the challenges of pregnancy and the related changes.

\section{Additional Information \\ Disclosures}

Human subjects: Consent was obtained or waived by all participants in this study. King Fahad HospitalHofuf, Al-Ahsa, Saudi Arabia issued approval 34-EP-2021. Informed consent was obtained from all the participants after describing the aim of the study, and the participants had autonomy for rejection. Privacy and confidentiality of results were maintained. Animal subjects: All authors have confirmed that this study did not involve animal subjects or tissue. Conflicts of interest: In compliance with the ICMJE uniform disclosure form, all authors declare the following: Payment/services info: All authors have declared that no financial support was received from any organization for the submitted work. Financial relationships: All authors have declared that they have no financial relationships at present or within the previous three years with any organizations that might have an interest in the submitted work. Other relationships: All authors have declared that there are no other relationships or activities that could appear to have influenced the submitted work.

\section{References}

1. Downe S, Finlayson K, Oladapo OT, Bonet M, Gülmezoglu AM: What matters to women during childbirth: a systematic qualitative review. PLoS One. 2018, 13:e0194906. 10.1371/journal.pone.0194906

2. Zeeni N, Abi Kharma J, Mattar L: Social media use impacts body image and eating behavior in pregnant women. [PREPRINT]. Curr Psychol. 2021, 10.1007/s12144-021-01848-8

3. Borge TC, Aase H, Brantsæter AL, Biele G: The importance of maternal diet quality during pregnancy on cognitive and behavioural outcomes in children: a systematic review and meta-analysis. BMJ Open. 2017, 7:e016777. 10.1136/bmjopen-2017-016777

4. Olson CM: Achieving a healthy weight gain during pregnancy. Annu Rev Nutr. 2008, 28:411-23. 10.1146/annurev.nutr.28.061807.155322

5. Duncombe D, Wertheim EH, Skouteris H, Paxton SJ, Kelly L: How well do women adapt to changes in their body size and shape across the course of pregnancy?. J Health Psychol. 2008, 13:503-15. $10.1177 / 1359105308088521$

6. Gagnon K, Sabus C: Professionalism in a digital age: opportunities and considerations for using social media in health care. Phys Ther. 2015, 95:406-14. 10.2522/ptj.20130227

7. Perloff RM: Social media effects on young women's body image concerns: theoretical perspectives and an agenda for research. Sex Roles. 2014, 71:363-77. 10.1007/s11199-014-0384-6

8. Lupton D: The use and value of digital media for information about pregnancy and early motherhood: a focus group study. BMC Pregnancy Childbirth. 2016, 16:171. 10.1186/s12884-016-0971-3

9. Kingston D, Tough S, Whitfield H: Prenatal and postpartum maternal psychological distress and infant development: a systematic review. Child Psychiatry Hum Dev. 2012, 43:683-714. 10.1007/s10578-012-02914

10. Fisher J, Cabral de Mello M, Patel V, Rahman A, Tran T, Holton S, Holmes W: Prevalence and determinants of common perinatal mental disorders in women in low- and lower-middle-income countries: a systematic review. Bull World Health Organ. 2012, 90:139G-49G. 10.2471/BLT.11.091850

11. Ding XX, Wu YL, Xu SJ, et al.: Maternal anxiety during pregnancy and adverse birth outcomes: a systematic review and meta-analysis of prospective cohort studies. J Affect Disord. 2014, 159:103-10. 10.1016/j.jad.2014.02.027

12. Alqahtani AH, Al Khedair K, Al-Jeheiman R, Al-Turki HA, Al Qahtani NH: Anxiety and depression during pregnancy in women attending clinics in a university hospital in eastern province of Saudi Arabia: prevalence and associated factors. Int J Womens Health. 2018, 10:101-8. 10.2147/IJWH.S153273

13. Dunkel Schetter C: Psychological science on pregnancy: stress processes, biopsychosocial models, and emerging research issues. Annu Rev Psychol. 2011, 62:531-58. 10.1146/annurev.psych.031809.130727

14. Lee AM, Lam SK, Sze Mun Lau SM, Chong CS, Chui HW, Fong DY: Prevalence, course, and risk factors for antenatal anxiety and depression. Obstet Gynecol. 2007, 110:1102-12. 
15. McDonald SW, Lyon AW, Benzies KM, et al.: The All Our Babies pregnancy cohort: design, methods, and participant characteristics. BMC Pregnancy Childbirth. 2013, 13:S2. 10.1186/1471-2393-13-S1-S2

16. Pampaka D, Papatheodorou SI, AlSeaidan M, et al.: Depressive symptoms and comorbid problems in pregnancy - results from a population based study. J Psychosom Res. 2018, 112:53-8. 10.1016/j.jpsychores.2018.06.011

17. Nath A, Venkatesh S, Balan S, Metgud CS, Krishna M, Murthy GV: The prevalence and determinants of pregnancy-related anxiety amongst pregnant women at less than 24 weeks of pregnancy in Bangalore, Southern India. Int J Womens Health. 2019, 11:241-8. 10.2147/IJWH.S193306

18. Niemi M, Falkenberg T, Petzold M, Chuc NT, Patel V: Symptoms of antenatal common mental disorders, preterm birth and low birthweight: a prospective cohort study in a semi-rural district of Vietnam. Trop Med Int Health. 2013, 18:687-95. 10.1111/tmi.12101

19. Huizink AC, Delforterie MJ, Scheinin NM, Tolvanen M, Karlsson L, Karlsson H: Adaption of pregnancy anxiety questionnaire-revised for all pregnant women regardless of parity: PRAQ-R2. Arch Womens Ment Health. 2016, 19:125-32. 10.1007/s00737-015-0531-2

20. Naja S, Al Kubaisi N, Singh R, Bougmiza I: Generalized and pregnancy-related anxiety prevalence and predictors among pregnant women attending primary health care in Qatar, 2018-2019. Heliyon. 2020, 6:e05264. 10.1016/j.heliyon.2020.e05264

21. Al-Menayes J: Psychometric properties and validation of the Arabic social media addiction scale . J Addict. 2015, 2015:291743. 10.1155/2015/291743

22. Tavakol M, Dennick R: Making sense of Cronbach's alpha. Int J Med Educ. 2011, 2:53-5. 10.5116/ijme.4dfb.8dfd

23. Dayan J, Creveuil C, Marks MN, Conroy S, Herlicoviez M, Dreyfus M, Tordjman S: Prenatal depression, prenatal anxiety, and spontaneous preterm birth: a prospective cohort study among women with early and regular care. Psychosom Med. 2006, 68:938-46. 10.1097/01.psy.0000244025.20549.bd

24. Sjögren B: Reasons for anxiety about childbirth in 100 pregnant women . J Psychosom Obstet Gynaecol. 1997, 18:266-72. 10.3109/01674829709080698

25. Huizink AC, Menting B, Oosterman M, Verhage ML, Kunseler FC, Schuengel C: The interrelationship between pregnancy-specific anxiety and general anxiety across pregnancy: a longitudinal study. J Psychosom Obstet Gynaecol. 2014, 35:92-100. 10.3109/0167482X.2014.944498

26. Nicholson WK, Setse R, Hill-Briggs F, Cooper LA, Strobino D, Powe NR: Depressive symptoms and healthrelated quality of life in early pregnancy. Obstet Gynecol. 2006, 107:798-806. 10.1097/01.AOG.0000204190.96352.05

27. Dunkel Schetter C, Tanner L: Anxiety, depression and stress in pregnancy: implications for mothers, children, research, and practice. Curr Opin Psychiatry. 2012, 25:141-8. 10.1097/YCO.0b013e3283503680

28. Bayrampour H, Ali E, McNeil DA, Benzies K, MacQueen G, Tough S: Pregnancy-related anxiety: a concept analysis. Int J Nurs Stud. 2016, 55:115-30. 10.1016/j.ijnurstu.2015.10.023

29. Madhavanprabhakaran GK, Kumar KA, Ramasubramaniam S, Akintola AA: Effects of pregnancy related anxiety on labour outcomes: a prospective cohort study. J Res Nurs Midwifery. 2013, 2:96-103.

30. Jha S, Salve HR, Goswami K, Sagar R, Kant S: Burden of common mental disorders among pregnant women: a systematic review. Asian J Psychiatr. 2018, 36:46-53. 10.1016/j.ajp.2018.06.020 